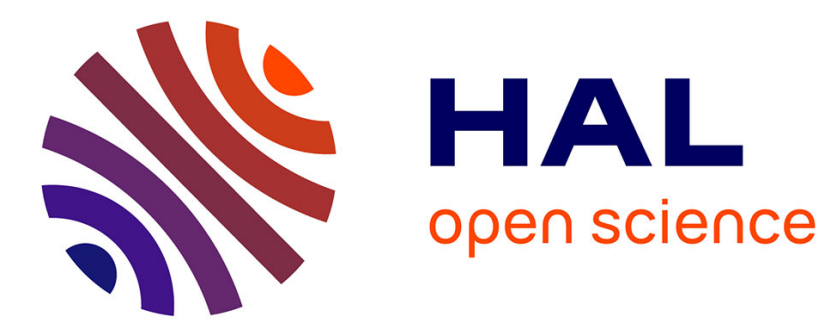

\title{
Photoconductivity in amorphous thin films of Ge22Se68Bi 10
}

\author{
R. Mathur, A. Kumar
}

\section{To cite this version:}

R. Mathur, A. Kumar. Photoconductivity in amorphous thin films of Ge22Se68Bi 10. Revue de Physique Appliquée, 1986, 21 (10), pp.579-584. 10.1051/rphysap:019860021010057900 . jpa00245475

\section{HAL Id: jpa-00245475 https://hal.science/jpa-00245475}

Submitted on 1 Jan 1986

HAL is a multi-disciplinary open access archive for the deposit and dissemination of scientific research documents, whether they are published or not. The documents may come from teaching and research institutions in France or abroad, or from public or private research centers.
L'archive ouverte pluridisciplinaire HAL, est destinée au dépôt et à la diffusion de documents scientifiques de niveau recherche, publiés ou non, émanant des établissements d'enseignement et de recherche français ou étrangers, des laboratoires publics ou privés. 


\title{
REVUE DE PHYSIQUE APPLIQUÉE
}

Revue Phys. Appl. 21 (1986) 579-584

OCTOBRE 1986, PAGE 579

Classification

Physics Abstracts

$72.80-73.60$

\section{Photoconductivity in amorphous thin films of $\mathrm{Ge}_{22} \mathrm{Se}_{68} \mathrm{Bi}_{10}\left(^{*}\right)$}

\author{
R. Mathur and A. Kumar \\ Department of Physics, Harcourt Butler Technological Institute, Kanpur, 208002, India
}

(Reçu le 10 octobre 1985, révisé le 14 avril 1986, accepté le 20 juin 1986)

\begin{abstract}
Résumé. - La dépendance, en température et en intensité d'illumination, de la photoconductivité à l'état stationnaire est étudiée dans des films minces amorphes de $\mathrm{Ge}_{22} \mathrm{Se}_{68} \mathrm{Bi}_{10}$ préparés par évaporation sous vide. La photoconductivité croît exponentiellement avec la température entre $310 \mathrm{~K}$ et $410 \mathrm{~K}$ et aucun maximum n'est trouvé dans ce domaine de température. Le rapport $I_{\mathrm{ph}} / I_{\mathrm{d}}$ vaut environ 6 à $310 \mathrm{~K}$ et a une décroissance continue quand la température crô̂t. Avec l'intensité, la photoconductivité suit une loi en puissance dont l'exposant $(\gamma)$ varie de 0,86 à 0,62 quand la température passe de $310 \mathrm{~K}$ à $380 \mathrm{~K}$. La photoconductivité transitoire et les courants stimulés thermiquement (CST) ont aussi été mesurés sur le même échantillon. Une décroissance non exponentielle de la photoconductivité est observée ; elle est très lente à température ambiante dans ce matériau. Un pic du CST est observé à $365 \mathrm{~K}$. Les mesures indiquent la présence d'une distribution continue d'états localisés dans les films minces de $\mathrm{Ge}_{22} \mathrm{Se}_{68} \mathrm{Bi}_{10}$.
\end{abstract}

\begin{abstract}
Temperature and intensity dependence of steady state photoconductivity is studied in amorphous thin films of $\mathrm{Ge}_{22} \mathrm{Se}_{68} \mathrm{Bi}_{10}$ prepared by vacuum evaporation. Photoconductivity increases exponentially with temperature between $310 \mathrm{~K}$ and $410 \mathrm{~K}$ and no maxima is found in this temperature range. The ratio $I_{\mathrm{ph}} / I_{\mathrm{d}}$ is about 6 at $310 \mathrm{~K}$ and decreases continuously as temperature is increased. Photoconductivity with intensity follows a power law where the power $(\gamma)$ varies from 0.86 to 0.62 as the temperature is increased from $310 \mathrm{~K}$ to $380 \mathrm{~K}$. Transient photoconductivity and thermally stimulated currents have also been measured on the same sample. A non-exponential decay of photoconductivity is observed which is very slow at room temperature in this material. A peak in TSC is observed at $365 \mathrm{~K}$. The present measurements indicate the presence of continuous distribution of localized states in thin films of $\mathrm{Ge}_{22} \mathrm{Se}_{68} \mathrm{Bi}_{10}$.
\end{abstract}

\section{Introduction.}

The measurement of photoconductivity is an important tool to understand the recombination kinetics which, in turns, give informations about the localized state in amorphous semiconductors. From the application point of view also, photoconductivity measurements are very important.

A variety of chalcogenide glasses have been studied [1-10] in bulk or in thin film form and various models [11-15] have been suggested to explain the results of photoconductivity. A maxima in photoconductivity is observed near room temperature in most

(*) Work supported by University Grants Commission, New Delhi, India. of the glassy alloys [1-6]. However, this maxima is not seen in some of the alloys [7-9]. Similarly, the intensity dependence of photoconductivity is not same in all the glassy alloys. A linear dependence on light intensity is reported $[1,10]$ in some alloys near room temperature. On the other hand, some alloys $[10,12]$ show square root dependence in the same temperature range.

The above discussion shows that photoconductivity results are highly intriguing in chalcogenide glasses. More and more experimental data is needed before putting a general model for photoconductivity in these glasses.

The present paper reports the photoconductivity measurements on amorphous thin films of $\mathrm{Ge}_{22} \mathrm{Se}_{68} \mathrm{Bi}_{10}$ prepared by vacuum evaporation. The 
alloys of $\mathrm{Ge}-\mathrm{Se}-\mathrm{Bi}$ have recently drawn great attention as the nature of conduction can be changed in these alloys from $\mathrm{p}$ type to $\mathrm{n}$ type by changing the concentration of $\mathrm{Bi}[16]$.

Steady state photoconductivity is studied as a function of temperature ( $310 \mathrm{~K}$ to $410 \mathrm{~K}$ ) at various levels of illumination. Intensity dependence of photoconductivity is also studied at various fixed temperatures ranging from $310 \mathrm{~K}$ to $380 \mathrm{~K}$.

Transient photoconductivity is studied at $310 \mathrm{~K}$ at various levels of illumination. The method of thermally stimulated currents has also been employed to study the deep traps in this material.

Section 2 describes the method of sample preparation and the experimental details of the measurements. The results of steady state and transient photoconductivity have been described and discussed in section 3. The last section deals with the conclusion of the present work.

\section{Experimental.}

Glassy alloy of $\mathrm{Ge}_{22} \mathrm{Se}_{68} \mathrm{Bi}_{10}$ was prepared by quenching technique. $99.999 \%$ pure materials $(\mathrm{Ge}, \mathrm{Se}$ and $\mathrm{Bi}$ ) were weighed according to their atomic percentages and were sealed in a quartz ampule (length $5 \mathrm{~cm}$, internal dia $8 \mathrm{~mm}$ ) in a vacuum of $\sim 10^{-5}$ torr. The sealed ampule was kept inside a furnace where the temperature was raised to $9500^{\circ} \mathrm{C}$ at the rate of $3-4{ }^{\circ} \mathrm{C} / \mathrm{min}$. The ampule was frequently rocked for 10 hours at the maximum temperature $\left(950^{\circ} \mathrm{C}\right)$. The quenching was done by taking the ampule out of the furnace and blowing room temperature air by an air blower.

Amorphous films of $\mathrm{Ge}_{22} \mathrm{Se}_{68} \mathrm{Bi}_{10}$ were prepared by vacuum evaporation in a vacuum of $\sim 10^{-5}$ torr keeping the substrates at room temperature. Thick Nichrome electrodes were deposited on well degassed corning glass substrates before depositing the amorphous films of $\mathrm{Ge}_{22} \mathrm{Se}_{68} \mathrm{Bi}_{10}$. The planar structures of amorphous films had the width of $2 \mathrm{~mm}$ and length $5 \mathrm{~mm}$. The thickness of the amorphous films were about $5000 \AA$. d.c. conductivity and the activation energy was found to be the same in bulk as well as in thin films of $\mathrm{Ge}_{22} \mathrm{Se}_{68} \mathrm{Bi}_{10}$.

Photoconductivity in thin films of $\mathrm{Ge}_{22} \mathrm{Se}_{68} \mathrm{Bi}_{10}$ was studied in a vacuum of $\sim 10^{-5}$ torr by mounting the sample in a cryostat which had a transparent window to shine light on the sample. The heater was mounted inside the cryostat. The temperature was measured by a calibrated copper-constantan thermocouple.

Thin film samples of $\mathrm{Ge}_{22} \mathrm{Se}_{68} \mathrm{Bi}_{10}$ were found ohmic in dark as well as in presence of light upto the maximum voltage $(9.3 \mathrm{~V})$ applied during the present measurements at all the measuring temperatures $(310 \mathrm{~K}$ to $410 \mathrm{~K})$. The photocurrent $\left(I_{\mathrm{ph}}\right)$ was obtained after subtracting the dark current $\left(I_{\mathrm{d}}\right)$ from the measured current $\left(I_{\mathrm{L}}\right)$ in the presence of light. The current was measured by a digital Picoammeter (Achme, model SD-100).
All the measurements reported in this paper were made by shining white light from a $200 \mathrm{~W}$ tungsten lamp. The intensity was varied by changing the voltage across the lamp. The relative intensity was measured by measuring short circuit current in a photocell. Proper care was taken to avoid the thermal effect of light.

For the measurement of transient photoconductivity, the light from a $200 \mathrm{~W}$ tungsten lamp was shone on the sample in a vacuum of $\sim 10^{-5}$ torr and the rise of the photocurrent was noted. When the saturation is reached, the light was put off and the decay of the current was noted with time.

Thermally stimulated currents (TSC) measurements were made by shining white light from a $200 \mathrm{~W}$ tungsten lamp for $10 \mathrm{~min}$ at room temperature keeping the sample in a vacuum of $\sim 10^{-5}$ torr. After reaching the steady state, the light was turned off and the photocurrent was allowed to decay for $12 \mathrm{~min}$. The sample was then heated at a constant rate and the resulting current was noted with temperature. TSC was obtained by subtracting dark current from the measured current after exciting the sample by light at $310 \mathrm{~K}$.

\section{Results and discussions.}

3.1 STEADY STATE PHOTOCONDUCTIVITY. - Temperature dependence of steady state photoconductivity is studied at three intensities and the results are plotted in figure 1 . These measurements were taken at a constant heating rate of $0.5 \mathrm{~K} / \mathrm{min}$. Figure 1 also contains a plot of dark current which is also measured at the same heating rate.

Figure 1 shows that $\ln I_{\mathrm{ph}} v s .1000 / T$ curves are straight lines at all the levels of illumination which

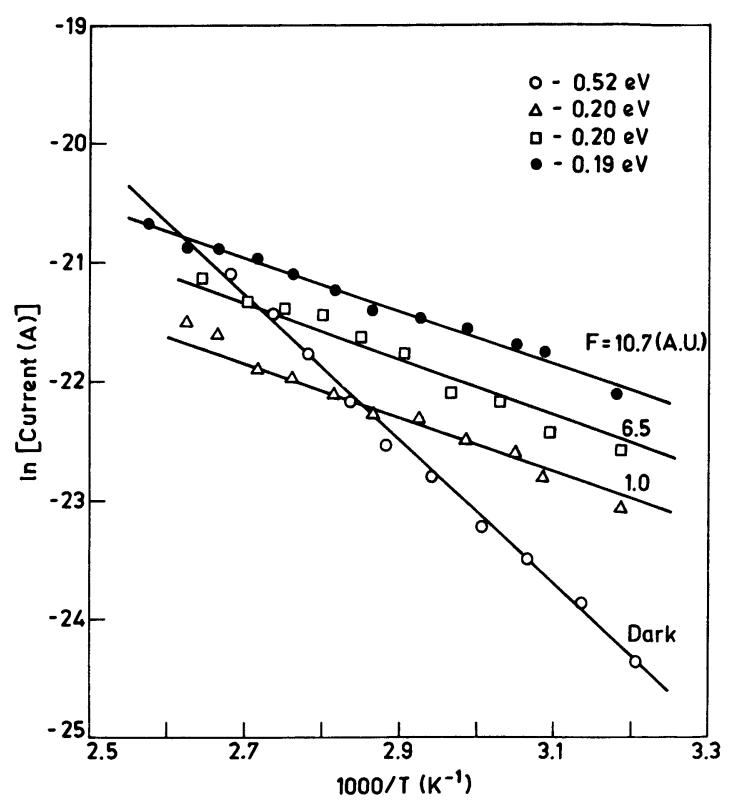

Fig. 1. - Dark current and photocurrent vs. $1000 / T$ at various levels of illumination. The voltage applied across the sample is $1.46 \mathrm{~V}$. 
shows that photoconductivity is an activated process. The slopes of these curves are between 0.19 and $0.20 \mathrm{eV}$. This shows that activation energy for photoconduction does not change with the level of illumination significantly. The activation energy for dark conduction is $0.52 \mathrm{eV}$ which is much higher than the activation energy for photoconduction. Similar results have also been reported in various other alloys [17].

The photocurrent at room temperature is much higher than the corresponding dark current at the highest intensity used. As the temperature increases, the ratio $I_{\mathrm{ph}} / I_{\mathrm{d}}$ decreases and, at higher temperatures around $400 \mathrm{~K}, I_{\mathrm{ph}}$ becomes smaller than $I_{\mathrm{d}}$ at all the levels of illumination. This type of behaviour is observed for a variety of chalcogenide glasses [1-6] where $I_{\mathrm{ph}}$ is found to be smaller than $I_{\mathrm{d}}$ at temperatures above room temperature. However, in contrast with others [1-6], the maxima in $I_{\mathrm{ph}}$ is not observed in the present case. Our results are in agreement with Shiah and Bube [7] who also could not observe maxima in photoconductivity for some of the glassy alloys. Shiah and Bube found that maxima is not observed in those materials in which photoconductivity is much less than the dark conductivity at room temperature. In the present case, though the photoconductivity is much more than dark conductivity at room temperature, yet a maxima is not seen in the photoconductivity in the temperature range $310 \mathrm{~K}$ to $410 \mathrm{~K}$.

While studying the photoconductivity in pure and silver doped As-Ge-Te alloys, Panwar et al. [9] could also not observe the maxima in photoconductivity upto $380 \mathrm{~K}$. In their samples also, photoconductivity was more than the dark conductivity at room temperature.

The above discussion shows that the maxima in photoconductivity with temperature should not be considered as a general behaviour of chalcogenide glasses.

Intensity $(F)$ dependence of photoconductivity is also studied at various fixed temperatures $(310,335$ and $380 \mathrm{~K})$. The results are plotted in figure 2 . It is clear from this figure that, at all the temperatures, In $I_{\mathrm{ph}} v s . \ln F$ curves are nearly straight lines which indicates that photoconductivity follows a power law with intensity $\left(\sigma_{\mathrm{ph}} \alpha F^{\gamma}\right)$. The power $\gamma$ has been calculated from the slopes of $\ln I_{\mathrm{ph}} v s . \ln F$ curves and the values are inserted in figure 2 . The value of $\gamma$ decreases from 0.86 to 0.62 as the temperature is increased from $310 \mathrm{~K}$ to $380 \mathrm{~K}$ (see Fig. 2).

In case of a semiconductor with only one type of recombination centres, the excess electron density $(\Delta n)$ can be related to the generation rate $(g)$ as follows [17]

$$
g=C_{n}\left(\Delta n^{2}+2 n_{0} \Delta n\right)
$$

where $C_{n}$ is the capture coefficient (the product of capture cross section and the thermal velocity of the carrier). $n_{0}$ is the density of thermal carriers. In the

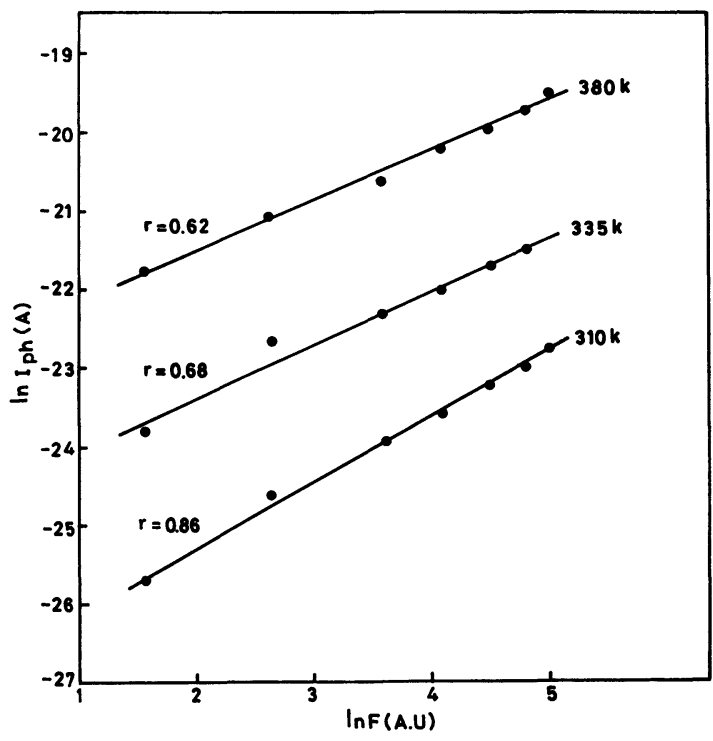

Fig. 2. - Intensity dependence of photocurrent at various temperatures. Voltage applied across the sample is 9.3 volts.

case of monomolecular recombination where $n_{0} \gg \Delta n$, equation (1) reduces to

$$
\Delta n=\frac{g}{2 C_{n} n_{0}} .
$$

As the generation rate is proportional to the light intensity $(F)$, the photoconductivity will vary linearly with light intensity in the above case. In case of bimolecular recombination where $n_{0} \ll \Delta n$, equation (1) reduces to

$$
\Delta n=\left(\frac{g}{C_{n}}\right)^{1 / 2} .
$$

Equation (3) shows that the photoconductivity will be proportional to square root of the light intensity in case of bimolecular recombination.

From the above discussion, it is clear that in both types of recombinations discussed above, photoconductivity follows a power law with light intensity, i.e., $\sigma_{\mathrm{ph}} \alpha F^{\gamma}$ where $\gamma=1$ for monomolecular recombination and $\gamma=0.5$ for bimolecular recombination.

Rose [18] has pointed out that the power $(\gamma)$ between 0.5 and 1.0 can not be understood by assuming a set of discrete trap levels but demands the existence of continuous distribution of traps in the band gap.

In the present case, $\gamma$ is always between 0.5 and 1.0 at various temperatures $(310 \mathrm{~K}$ to $380 \mathrm{~K})$ which indicates that a continuous distribution of localized states exists in the mobility gap of $\mathrm{Ge}_{22} \mathrm{Se}_{68} \mathrm{Bi}_{10}$.

3.2 TRANSIENT PHOTOCONDUCTIVITY. - Transient photoconductivity is studied at $310 \mathrm{~K}$ at various 
levels of illumination. The results are plotted in figure 3. It is clear from this figure that the rise and decay of the photocurrent is very slow in this material. The photocurrent gets saturated in about $7 \mathrm{~min}$. After turning the light off, the photocurrent first decreases rapidly and then much more slowly. Even after decaying for $12 \mathrm{~min}$, the photocurrent does not go to zero. At the higher intensities, the fast component is much more as compared to the slow component (see Fig. 3).

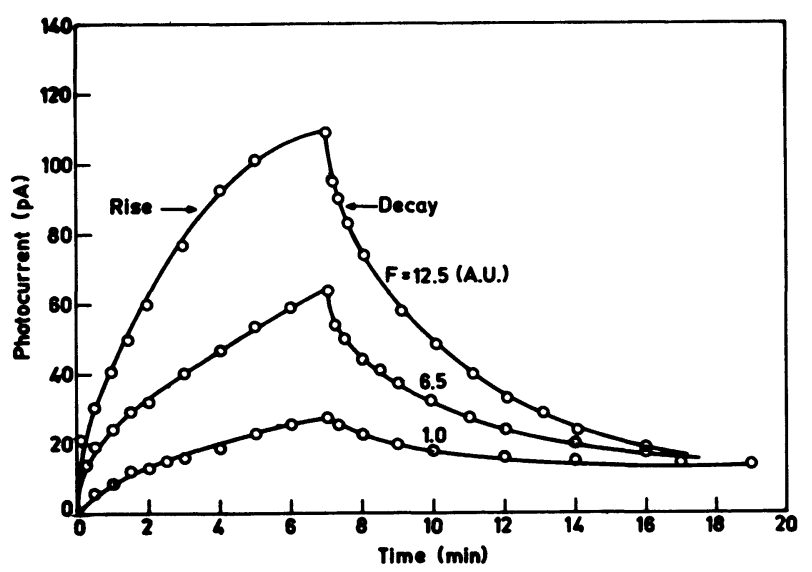

Fig. 3. - Rise and decay of photocurrent at $310 \mathrm{~K}$ at various levels of illumination. Voltage applied across the sample is 9.3 volts.

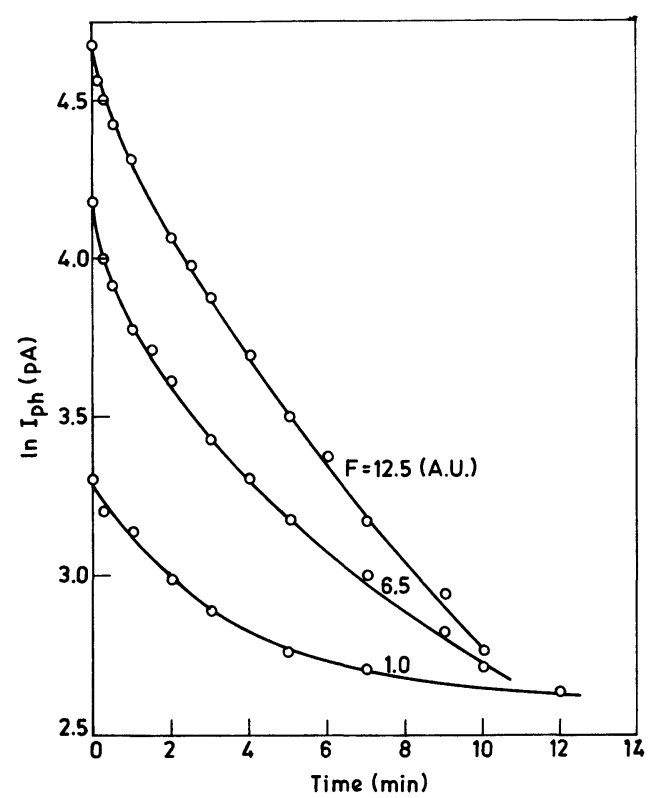

Fig. 4. - In $I_{\mathrm{ph}} v s$. time curve for the decay of photocurrent at $310 \mathrm{~K}$. The data has been taken from figure 3 .

Figure 4 shows the plots of $\ln I_{\mathrm{ph}} v s$. time $(t)$ for the decay of photocurrent at various intensities. These curves are not straight lines and the slope goes on decreasing continuously (see Fig. 4). In case of semiconductor having single trap level, the variation of the density of free carriers, neglecting the retrapping, during the decay can be written as [19]

$$
\Delta n=n_{\mathrm{t} 0} \tau P \mathrm{e}^{-P t}
$$

where $n_{\mathrm{t} 0}$ is the total number of trapped carriers, $\tau$ is the life time and $P$ is the probability of an electron escaping from a trap with trap depth $E$ and capture coefficient $C_{n}$ and is given by

$$
P=N_{0} C_{n} \exp \left(\frac{-E}{k T}\right)
$$

where $N_{0}$ is the effective density of states in the conduction band.

From equation (4) it is clear that, in case of single trap level, the photoconductivity which is proportional to $\Delta n$ will decay exponentially with time. The slope of $\ln \sigma_{\mathrm{ph}}$ vs. time curve can be used to calculate the trap depth using equation (5). However, if there are different kinds of traps having distribution with energy $E$, the resulting decay curve will have many exponentials of the type given in equation (4) and hence the plot of $\ln \sigma_{\mathrm{ph}} v s$. $t$ will not give one particular slope.

As the slope of figure 4 goes on decreasing with time, one expects that deeper and deeper traps are emptying as time elapses. These results show the presence of the continuous distribution of localized states in this material. Shimakawa et al. [10] have also observed the same type of behaviour in the bulk samples of Te-Se-Sb alloys at room temperature.

For the further study of the traps in this material, the technique of TSC was employed. After exciting the sample by $200 \mathrm{~W}$ tungsten lamp at $310 \mathrm{~K}$, the sample was heated at a constant rate of $10 \mathrm{~K} / \mathrm{min}$ in dark and the resulting current with temperature is plotted in figure 5. The same figure also contains the dark current measured at the same rate before exposing the sample to light.

It is clear from figure 5 that the current measured after exposing the sample to light is higher than the dark current. The two curves in figure 5 seem to meet at higher temperatures (more than $390 \mathrm{~K}$ ). The difference of these two curves is plotted against temperature in figure 6. This difference is known as Thermally Stimulated Current. It is clear from figure 6 that TSC shows a maxima at about $365 \mathrm{~K}$. Using an approximate formula [20] for the trap depth $\left(25 k T_{\max }\right)$, one can estimate the trap depth which comes out to be $0.78 \mathrm{eV}$.

The maxima in TSC above room temperature should, however, not always be interpreted as the presence of single trap level. A system having a continuous distribution of localized states can also show a broad maxima at higher temperatures [21]. Further measurement on TSC in $\mathrm{Ge}_{22} \mathrm{Se}_{68} \mathrm{Bi}_{10}$ are in progress and the results will be communicated elsewhere. 


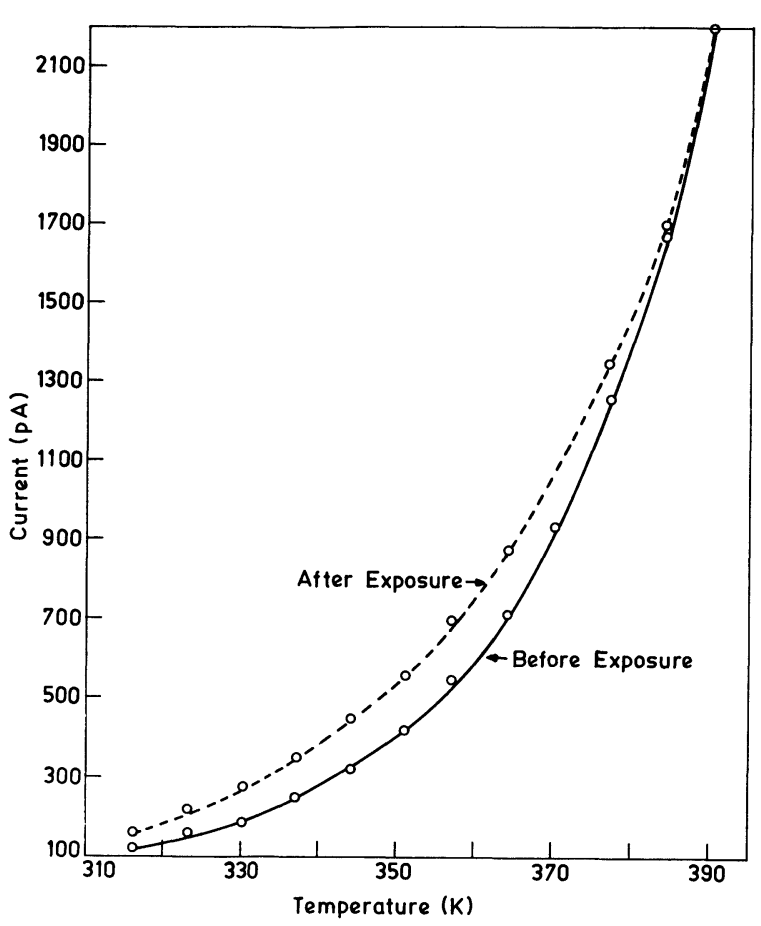

Fig. 5. - Dark current versus temperature before and after white light exposure at $310 \mathrm{~K}$ for $10 \mathrm{~min}$. The voltage applied across the sample is $1.46 \mathrm{~V}$.

\section{Conclusion.}

Temperature dependence of steady state photoconductivity is studied in $\mathrm{Ge}_{22} \mathrm{Se}_{68} \mathrm{Bi}_{10}$ amorphous thin films prepared by vacuum evaporation. No maxima in photoconductivity is observed in the working temperature range ( $310 \mathrm{~K}$ to $410 \mathrm{~K})$ and the photoconductivity is found to be an activated process having single activation energy which is much smaller than the activation energy for dark conduction.

Intensity dependence of photoconductivity has also been studied at various temperatures, $\gamma$ varies from 0.86 to 0.62 as the temperature is increased from $310 \mathrm{~K}$ to $380 \mathrm{~K}$.

Transient photoconductivity is studied at room temperature. The rise and decay is found to be very slow in this material. The residual photoconductivity

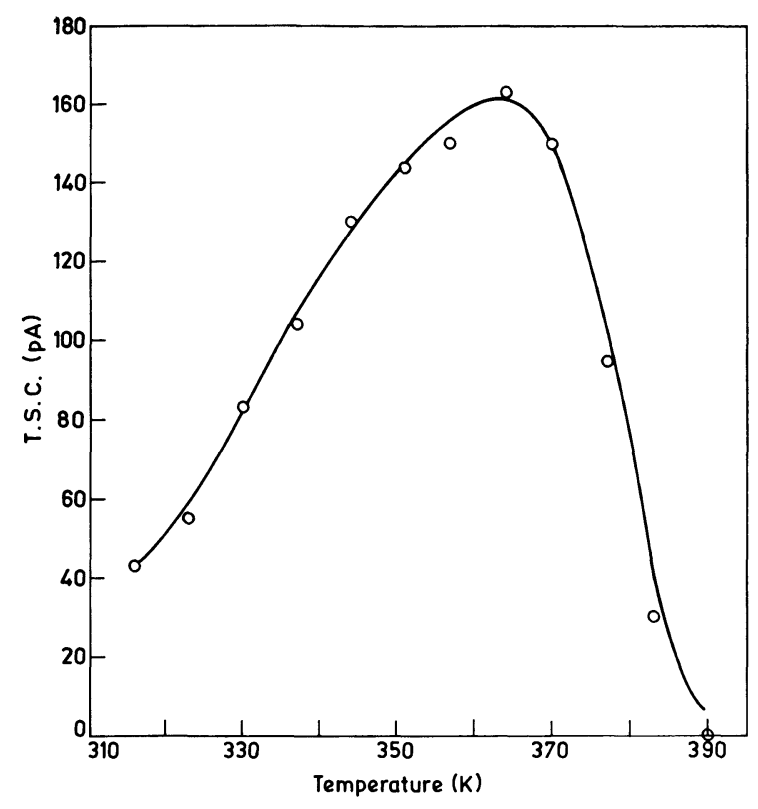

Fig. 6. - Thermally stimulated currents versus temperature. The data has been taken from figure 5 .

is observed at room temperature even after decaying for $12 \mathrm{~min}$. Thermally stimulated currents have also been observed which show a maxima around $365 \mathrm{~K}$.

The value of $\gamma$ between 0.5 and 1.0, non-exponential decay of photoconductivity and the presence of residual photoconductivity at room temperature indicate that the continuous distribution of localized states exists in the mobility gap of this material.

The observation of TSC and a maxima around $365 \mathrm{~K}$ also confirm the above statement. Though the exact distribution could not be obtained from the present measurements, the results suggest that a set of discrete levels can not explain the present results.

\section{Acknowledgements.}

We are grateful to Prof. A. N. Nigam for his help in the experimental set up and to Dr D. N. S. Srivastava for various discussions during the course of this work.

\section{References}

[1] Fagen, E. A. and Fritzsche, H., J. Non-Cryst. Solids 4 (1970) 480.

[2] Arnoldussen, T. C., Bube, R. H., Fagen, E. A. and Holmberg, S., J. Appl. Phys. 43 (1972) 1798.

[3] Marshall, J. M., Main, C. and Owen, E. E., J. Non-Cryst. Solids 8-10 (1972) 760.

[4] Bube, R. H., Mahan, H. E., Shiah, R. T. S. and VAN Der Plas, H. A., Appl. Phys. Lett. 25 (1974) 419.
[5] Taylor, G. W. and Simmons, J. G., J. Phys. C 7 (1974) 3067.

[6] Moustakas, T. D. and Weiser, K., Phys. Rev. B 12 (1975) 2448.

[7] Shiah, R. T. S. and Bube, R. H., J. Appl. Phys. 47 (1976) 2005.

[8] Igalson, M. and Trykozko, R., Solid State Commun. 40 (1981) 99.

[9] Panwar, O. S., Srivastava, K. K. and LakshmiNARAYAN, K. N. (unpubl ished work). 
[10] Shimakawa, K., Yoshida, A. and Arizumi, T., J. Non. Cryst. Solids 16 (1974) 258.

[11] WeISER, K., J. Non-Cryst. Solids 8-10 (1972) 922.

[12] Arnoldussen, T. C., Bube, R. H., Fagen, E. A. and Holmberg, S., J. Non-Cryst. Solids 8-10 (1972) 933.

[13] Simmons, J. G. and Taylor, G. W., J. Phys. C 6 (1973) $3706 ; 7$ (1974) 3051.

[14] Halpern, V., Philos. Mag. B 37 (1978) 423.

[15] ARkHIPOV, V. I., Sov. Phys. Semicond. (USA) 16 (1982) 1336.

[16] Nagels, P., Rotti, M. and Vikhrov, S., 9th Int.
Conf. Amorphous and Liquid Semiconductors, July 1981, Grenoble (France).

[17] Nagels, P., in Amorphous Semiconductors, edited by M. H. Brodsky (Springer-Verlag, Berlin, Heidelberg) 1979.

[18] Rose, A., Concepts in Photoconductivity (Interscience, New York) 1963.

[19] BubE, R. H., Photoconductivity of Solids (John Wiley and Sons, Inc., New York) 1960.

[20] Fuhs, W. and Milleville, H., Phys. Status Solidi B 98 (1980) K29.

[21] Misra, D. S., Kumar, A. and Agrawal, S. C., Phys. Rev. B 31 (1985) 1047. 